\title{
PROBLEMS WITH THE USE OF PNEUMATIC SCREW PUMPS TO TRANSPORT BULK CARGO
}

\author{
S. Ya. Davydov, ${ }^{1}$ N. P. Kosarev,${ }^{1}$ N. G. Valiev, ${ }^{1}$ D. I. Simisinov, ${ }^{2}$ \\ G. G. Kozhushko' , and D. A. Panov ${ }^{3}$
}

Translated from Novye Ogneupory, No. 3, pp. 139 - 144, March, 2013.

Original article submitted December 13, 2012.

An analysis is made of the performance of pneumatic screw pumps at the Bereznikovsky Soda Plant in order be able to transport light soda along a prescribed route and make use of a new nozzle section to make the pumps' operation more reliable. Specific recommendations are made to increase the throughput and reliability of pneumatic screw pumps. The expediency of replacing long lines of screw pumps by chamber pumps is also discussed.

Keywords: pneumatic screw pump (PSP), productivity, light soda, transport pipe, compressed air, nozzles, modernization.

Continuous pneumatic screw pumps (PSPs) are designed to transport dust-sized or fine-grained materials along a conduit by means of compressed air. Pneumatic rotary pumps are used as feeders in the pneumatic conveyors employed by cement plants for the in-factory transport of cement. They serve the same function in plants that make ferroconcrete products and in factories that make products used in home construction. PSPs are also commonly used at plants in the chemical, metallurgical, glass, and cellulose-paper sectors, among other industries. There, they are employed in pneumatic conveyors that transport calcined soda, sodium sulfate, alumina, potassium chloride, phosphates, ash, coal dust, ores in powder form, fertilizers, and many other materials. The PSPs currently being built in Russia can convey materials over a distance of $230-430 \mathrm{~m}$, including $30 \mathrm{~m}$ vertically $[1-3]$.

At present, Russian industry makes four main types of PSPs. They range in capacity from 10 to 100 tons/h. The design of these pumps was initially the same as the design of the pumps made by the "Fuller" company in the U. S. The design of the main working elements of the Russian pumps was later modernized so as to significantly improve the pumps' service characteristics, durability, and reliability.

When operated under normal conditions and given the proper maintenance, pneumatic screw pumps perform reli-

1 Ural State Mining University, Ekaterinburg, Russia.

2 Ural Federal University, Ekaterinburg, Russia.

3 ZAO “ROSMASHINZHINIRING,” Ekaterinburg, Russia. ably over many years. On the average, PSPs last more than 10 yrs. Among the parts of PSPs that wears most rapidly is the fast-moving pumping screw. The length of the period of continuous operation of the screw is within the range $50-1000 \mathrm{~h}$, depending on the type of electrodes used. The bronze sleeve and the disk of the check valve undergo considerably less wear. The gland packings in the latest designs of the seal of the screw's shaft average $300-350 \mathrm{~h}$ of continuous use. To optimize the service life of the parts that wear quickly, it is necessary to regularly check the condition of the corresponding components.

The wear of the screw is determined by periodically measuring the gap between it and the sleeve. When the size of this gap reaches $5 \mathrm{~mm}$, the screw should be replaced and the worn screw reconditioned by hard-facing its turns with VSN-b electrodes. Electrodes of the T-590 or T-620 type can be used if VSN-b electrodes are not available, but such a substitution will result in a nearly twofold reduction in the remaining life of the screw. The hard-facing operation should be performed by a qualified welder. The hard-faced screw is machined on a specially equipped lathe to bring it to the necessary diameter. The frequency of preventive maintenance and reconditioning of the screw is determined in the course of operation of the pump. The wear of the sleeve is determined by measuring its diameter. The sleeve is allowed to be worn up to $3-4 \mathrm{~mm}$ per side and up to $6 \mathrm{~mm}$ when wear of the screw is also taken into account. The frequency with which the gland of the shaft's seal is refilled is determined 
visually by observing the performance of the pump. When light dust formation is seen, the gland should be tightened and the packing subsequently replaced. After a return-valve disk that does not have a rubber gasket has become worn, the disk should be checked together with the seat on a lathe and machined appropriately to the degree of wear. If the disk does have a rubber gasket, it is replaced when it wears.

In light of the new compositions of wear-resistance hard-facings that have been developed in recent years and the significant improvements that have been made in the design of the pumping screw, the maximum distance that the pump is allowed to transport materials can be increased to $500-800 \mathrm{~m}$ in order to reduce the screw's rate of wear.

One shortcoming of the well-known types of pneumatic conveyors is that an increase in pressure in the mixing chamber is accompanied by an increase in the resistance to movement of the material by the pumping screw and the infiltration of air into the charging chamber by way of the screw. Reverse movement of the material and the gas results in blockage of the nozzles, which adversely affects the reliability of the entire pneumatic conveyor. The injection of additional air to clear the unit requires a substantial quantity of compressed air.

The Bereznikovsky Soda Plant conducted tests of a pneumatic conveyor on PSP line No. 6 to boost its productivity by $20 \%$ or more. The plant uses Russian-made and foreign PSPs to transport light soda of grade B from calcination shop No. 1 to the department that makes calcined soda of grade B. Both types of pumps have required frequent replacement and have not provided the desired level of productivity. The granulometric composition of the light soda,

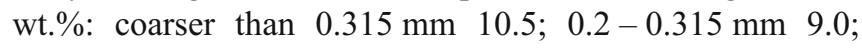
$0.16-0.2 \mathrm{~mm} \quad 7.4 ; 0.1-0.16 \mathrm{~mm} \quad 21.3 ; \quad 0.063-0.1 \mathrm{~mm}$ $20.9 ; 0.045-0.063 \mathrm{~mm} \mathrm{14.8}$; finer than $0.045 \mathrm{~mm} \mathrm{16.2}$. The specifications of the pneumatic conveyor are shown below:

Pressure of the incoming compressed air, MPa . . . . . . . . . . . 0.35

Temperature of the incoming compressed air, ${ }^{\circ} \mathrm{C} \ldots \ldots \ldots$

Diameter of the transport pipe, $\mathrm{mm}$. . . . . . . . . . . . 250

Temperature of the charged soda, ${ }^{\circ} \mathrm{C} \ldots \ldots \ldots \ldots$

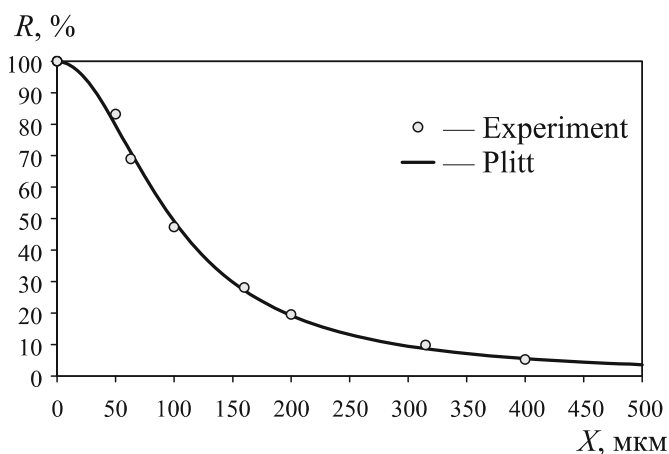

Fig. 1. Total-residue curve.

Density of the soda particles, $\mathrm{kg} / \mathrm{m}^{3} \ldots \ldots \ldots$. . . . . . . 1606

Bulk density of the soda, $\mathrm{kg} / \mathrm{m}^{3} \ldots \ldots \ldots 550$ Temperature of the two-phase flow in the steady-state regime, ${ }^{\circ} \mathrm{C} ~ \ldots 130$ Rated capacity, tons material $/ \mathrm{h}$. . . . . . . . . . . . . . 15 Maximum allowable pressure in the PSP chamber, MPa . . . . 0.15 Length of the transport pipe, $\mathrm{m}$. . . . . . . . . . . . . . . 280 Maximum elevation of the pipe, $\mathrm{m}$. . . . . . . . . . . . . . 40 Productivity based on the material transported, tons $/ \mathrm{h}$. . . . 5.4-7.4

A granulometric screen analysis showed that maximum particle size in the light soda is $0.5 \mathrm{~mm}$. The granulometric composition and integral curve of particle-size distribution are shown in Fig. 1 and Table 1.

Disassembly and detailed examination of one of the PSPs at the plant led to the recommendation to reposition the conveyor and use an aerodynamic base plate [5] in the pump's mixing chamber. This device allows the material being transported to undergo high-rate aeration by compressed air. The mixing chamber was also provided with a upgraded nozzle insert. Instead of 11 cylindrical nozzles $10 \mathrm{~mm}$ in diameter, the chamber now has ten ultrasonic 12-mm-diam. nozzles. The mixing chamber of the PSP was looked at as a ejector that sends bulk material into a pipe. The motive force of the ejector is an air jet emanating from an active nozzle. We used nozzles with a high discharge velocity (sonic and

TABLE 1. Granulometric Composition of the Soda

\begin{tabular}{|c|c|c|c|c|c|c|c|}
\hline Screen, $X_{\mathrm{s}}, \mu \mathrm{m}$ & Mean $X_{\mathrm{av}}, \mu \mathrm{m}$ & Residue $R, \%$ & Fraction $r, \%$ & Passed material $D, \%$ & \multicolumn{3}{|c|}{ Approximation of the total-residue curve $R=f(X)$} \\
\hline 400 & 450 & 5.20 & 5.20 & 94.80 & 5.54 & 1.81 & 4.29 \\
\hline 315 & 358 & 9.82 & 4.62 & 90.18 & 8.68 & 5.30 & 7.83 \\
\hline 200 & 258 & 19.54 & 9.72 & 80.47 & 19.22 & 19.69 & 19.66 \\
\hline 160 & 180 & 28.12 & 8.59 & 71.88 & 27.19 & 29.67 & 28.04 \\
\hline 50 & 57 & 83.21 & 14.21 & 16.80 & 79.67 & 76.58 & 79.55 \\
\hline 0 & 25 & 100.00 & 16.80 & 0.00 & 100.00 & 100.00 & 100.00 \\
\hline Curve steepness index $P$ & & & & & 2.021 & 1.303 & 0.024 \\
\hline Average size $X_{50}, \mu \mathrm{m}$ & & & & & 98.284 & 104.010 & 98.860 \\
\hline Standard deviation $S$ & & & & & 22.436 & 98.496 & 25.537 \\
\hline
\end{tabular}




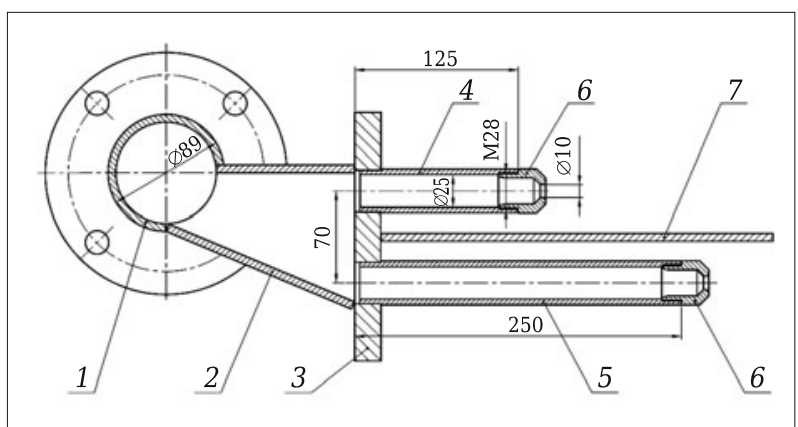

Fig. 2. Design of two-tier nozzle section.

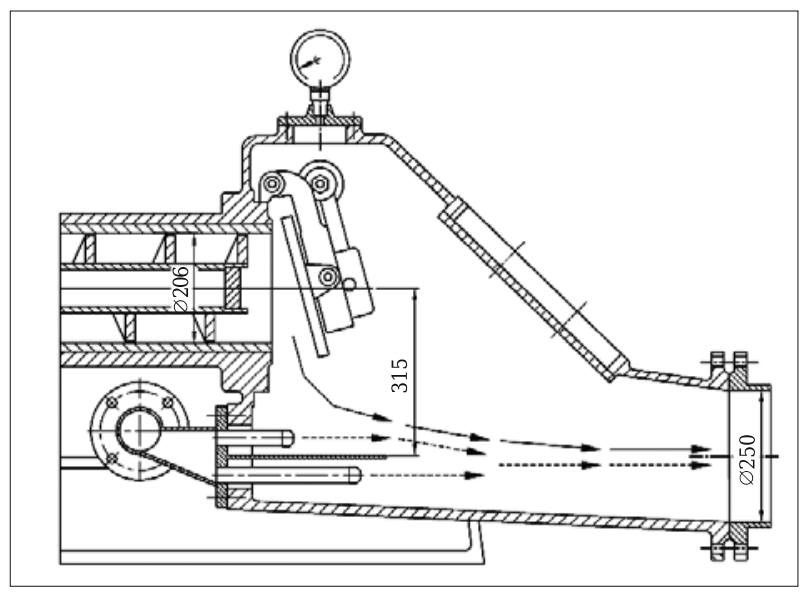

Fig. 3. Installation of the nozzle section in the chamber of a PSP.

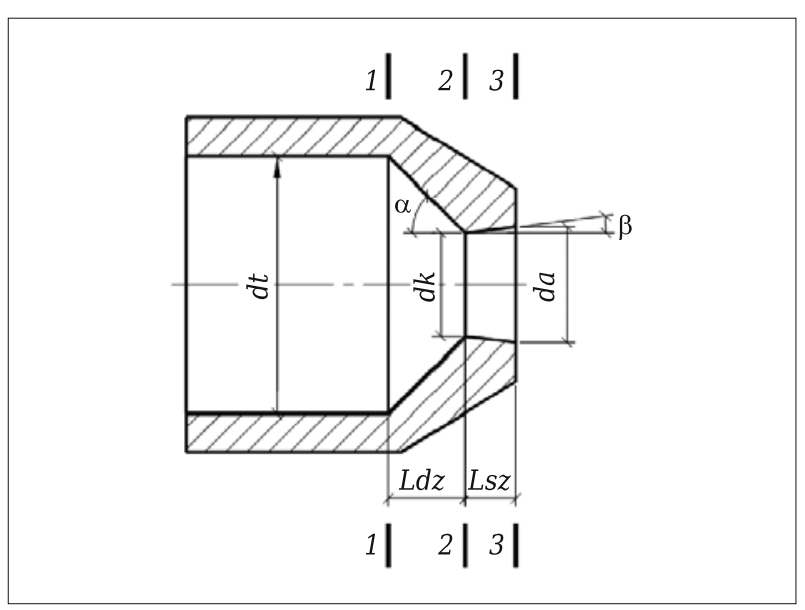

Fig. 4. Diagram of supersonic conical nozzle.

supersonic) in order to obtain the maximum possible draft. Figure 2 shows the upgraded nozzle section.

The nozzle section includes compressed-air feed line 1 , a distribution pipe 2, load-bearing panel-flange 3 , nozzle tubes 4 and 5 , nozzles 6 , and baffles 7 . The nozzles are arranged in two rows, with one row being located above the other. Each

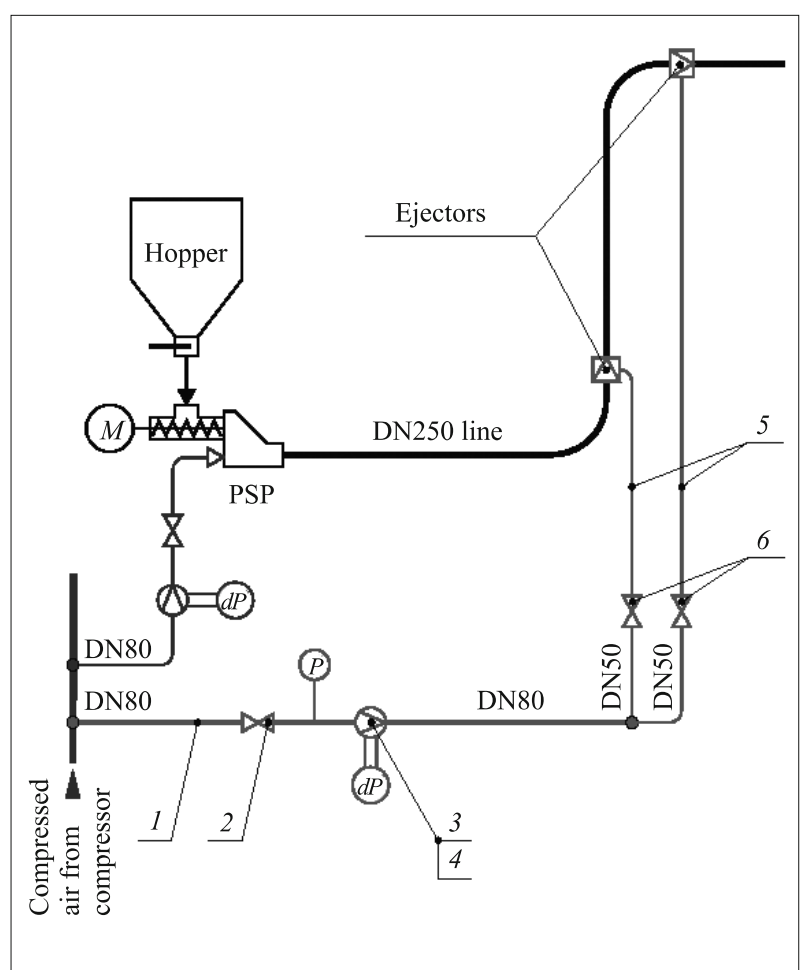

Fig. 5. Diagram of the installation of the ejectors: 1 ) DN80 air line; 2) DN80 PN10 ball valve; 3 ) DN80 diaphragm flowmeter; 4 ) differential manometer; 5 ) DN50 air line; 6) DN50 PN10 ball valve.

row contains five nozzles and has its own baffle. The functional capabilities of the proposed design are illustrated in Fig. 3. The new nozzle section makes it possible to increase the acceleration of the material being transported as a result of an increase in the length of the nozzle tubes and their separation into two sections in the height direction. The top row imparts the initial momentum to the material falling from the screw. Then the bottom row - which is separated from the top row by a horizontal baffle and has long tubes - imparts additional momentum to the material and directs it into the transport pipe. The baffle prevents rapid mixing of the jets from the nozzles of the top and bottom rows and the attendant loss of energy.

The supersonic nozzles can be specially shaped (such as in the form of de Laval nozzles) or conical. The pressure losses in the nozzles are only a small part of the total pressure losses. Thus, for this reason and the fact that they are simpler to make, supersonic conical nozzles are the type most commonly used in ejector units [4]. Figure 4 shows a supersonic conical nozzle. The gas has stagnation parameters in section $1-1$ and critical parameters in narrow section $2-2$. The parameters of the gas in discharge section $3-3$ correspond to the supersonic flow regime.

Foreign objects (grinding-ball fragments, nails, bolts, etc.) in the incoming bulk cement often end up in the gap between the screw and the sleeve during the operation of PSPs. This invariably leads to jamming of the screw and stoppage 
of the pump. In such cases, the electric motor needs to be turned off immediately and the object that caused the jam needs to be removed. No less frequent are cases in which the transport pipe is obstructed due to uneven feeding of the cement into the mixing chamber or disruptions in the compressed-air feed. The working pressure recorded in the mixing chamber by the manometer rises rapidly in these instances, and it becomes necessary to immediately stop the pumping screw and scavenge the pipe to reduce pressure in the chamber to the minimum level $\left(0.2-0.3 \mathrm{kgf} / \mathrm{cm}^{2}\right)$. Poor pump maintenance and delays in performing preventive maintenance on the screw, shell, and check valve or in repacking the gland can also lead to forced shutdowns of the conveyor. Figure 5 presents a diagram illustrating the installation of the ejectors, while Fig. 6 shows the installation of supersonic nozzles in the form of ejectors Nos. 1 and 2 along the route of the conveyor.

Studies performed at the factory led to recommendation of the following upgrade for the PSPs (Fig. 7) with allowance for the most similar prototypes [1-6]. Pneumatic screw pump 1 for the transport of bulk materials includes re- ceiving chamber 1 and mixing chamber 2 . The two chambers are connected to one another by housing 3, with pumping screw 4 being located inside the housing. Check valve 5 is installed in mixing chamber 2. Adjustable compressed-air nozzle 6 is located on housing 3 between the end of drive screw 4 and check valve 5 in mixing chamber 2 . A second adjustable valve 6 is located on transport pipe 7 . Valve 6 contains convergent section 9 supported by flange 9 . Conical duct 10 is located on top of section 8 . The inside surface of nozzle 10 has an annular internal recess 11 which is connected to the air supply line of compressed-air main 12. Conical nozzle 12 contains convergent inside surface 13. Annular gap 14 is formed by the surface of section 8 and the surface 13 of conical duct 10 . Valve 15 is installed on the air-supply line of air main 12 . At the outlet of nozzle 10 , the axis 16 of surface 13 is displaced in the downward direction at amount $\delta$ relative to the axis 17 of section 8 so as to form crescent-shaped gap 14 . The width of gap 14 can be regulated with screw 18 . To keep particles of the material from entering valve 15 and the main 12 that delivers compressed air, annular recess 11 is provided with a porous baffle 19 hav-

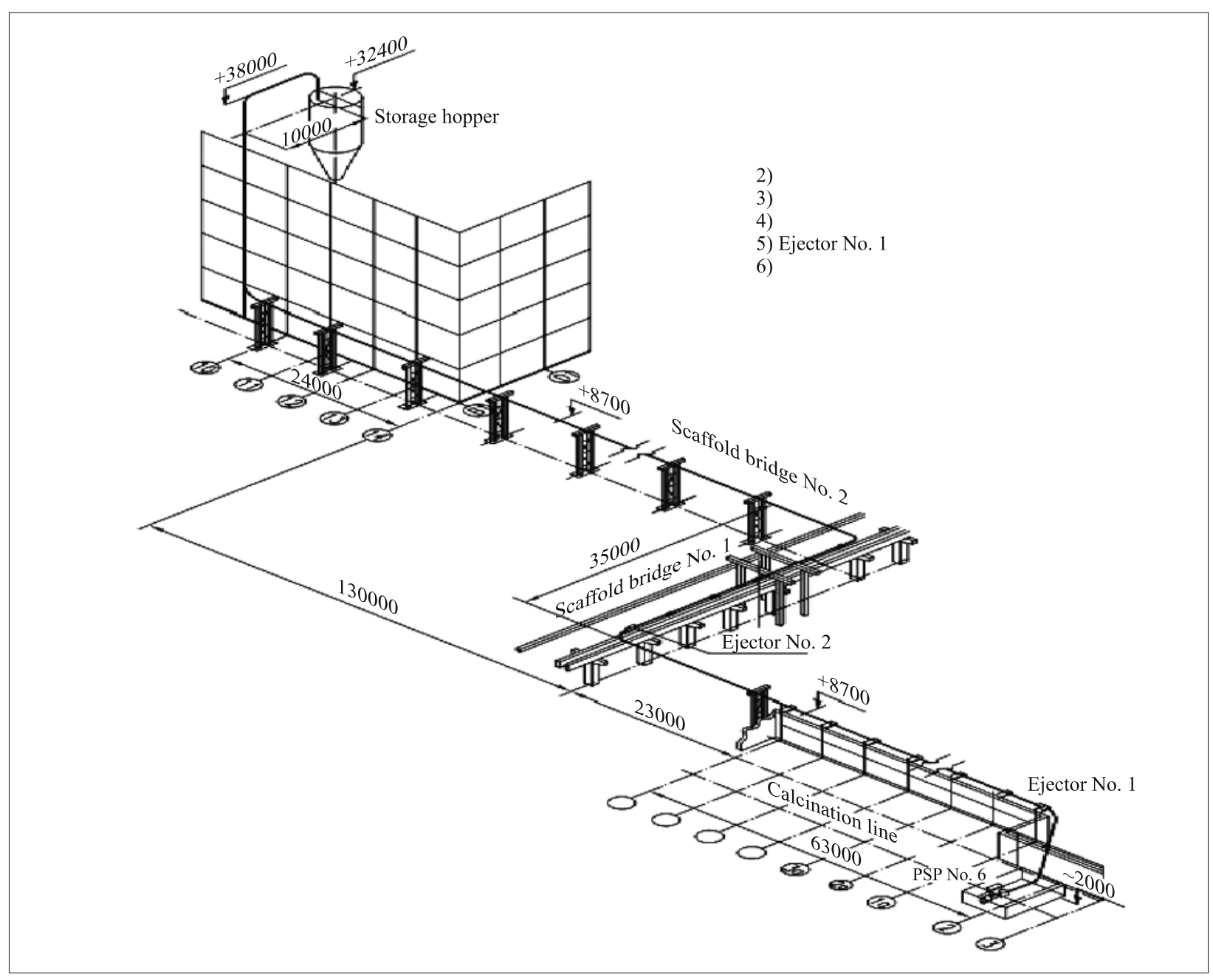

Fig. 6. Diagram of PSP transport line No. 6. 


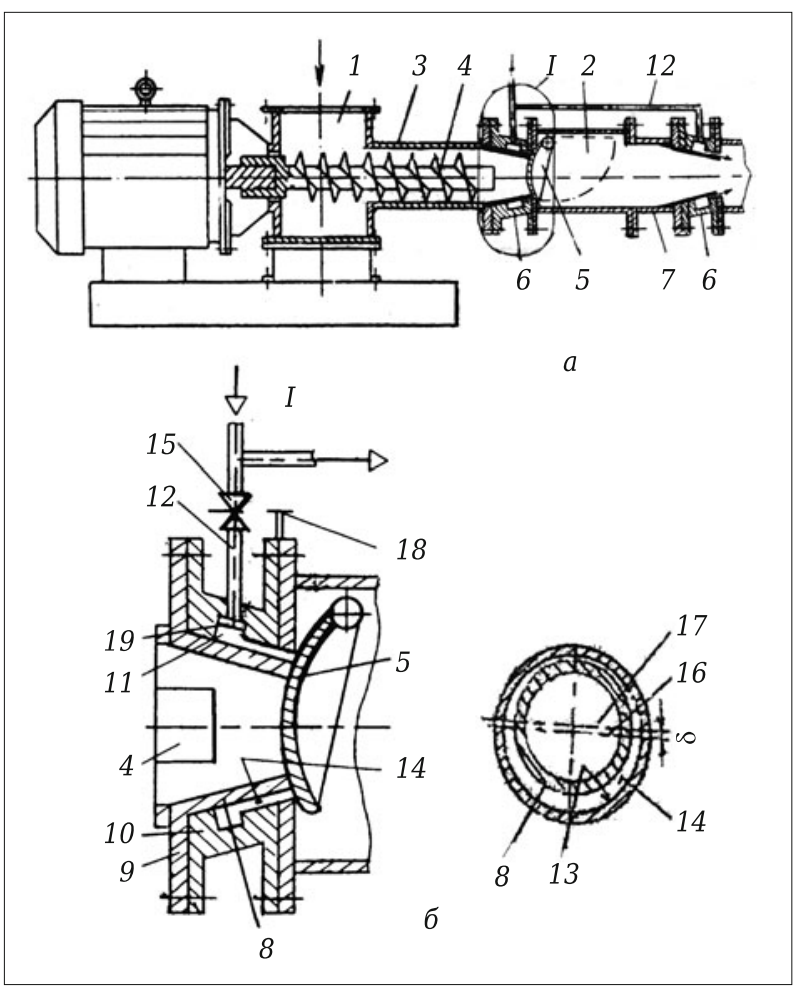

Fig. 7. Modernized bulk-materials PSP: $a$ ) general view of the PSP; $b$ ) opening in the form of a crescent-shaped slit.

ing a low resistance to the passage of compressed air (the baffle could be made of non-collapsible metal netting, for example). Porous baffle 19 functions as an aerating element.

The pneumatic screw pumps works in the following manner. The material being transported enters receiving chamber 1 and is fed into housing 3 by pumping screw 4 . As the bulk material enters convergent duct 10 of adjustable nozzle 6 - which is positioned after the last turn of screw 4 - it is pressed together to form a plug. The plug ensures consolidation of the material between receiving chamber 1 and mixing chamber 2 . In addition, the compressed material cannot penetrate the compressed air in the reverse direction in the event counter-pressure develops in the transport pipe.

After the compressed material leaves adjustable nozzle 6 , it is entrained by multiple jets of compressed air emanating from crescent-shaped slit 14 and is fed through mixing chamber 2 into transport pipe 7 . A large number of compressed-air jets is formed as a result of the presence of porous baffle 19 in annular recess 11 . The jets well-aerate the material being transported. In the event of reverse movement of the material-air medium when counter-pressure develops in transport pipe 7 , the porous baffle of the second nozzle 6 keeps particles of the material from entering main 12. In this case, nozzle 6 on housing 3 is closed by check valve 5 .

The existence of crescent-shaped slit 14 makes it possible to direct more of the compressed air into the lower internal part of the pipe, thus protecting the pipe wall from abrasive wear. This also reduces compressed-air consumption and allows the material to be transported a longer distance. The fact that the width of the crescent-shaped opening can be regulated is reflected both in the transport distance and the energy costs. Adjustable nozzle 6 is designed to form a plug of compressed material, supply the bulk of the material-conveying compressed air, ensure aeration of the material being transported and its movement along the pipe, and keep the material from entering the compressed-air line if counter-pressure should develop in the transport pipe.

Thus, the installation of adjustable nozzles ahead of the check valve and along the transport pipe reduces the energy costs incurred in transporting materials, makes the pneumatic conveyor more productive, increases the maximum transport distance, alleviates abrasive wear to the pipe, and improves the reliability and consistency of the transport system's performance. However, screw pumps need to be replaced by chamber-type pumps when materials have to be transported long distances.

No special comment need be made here on the increasing activity of foreign manufacturers in the equipment market for Russian industry. The equipment specifications claimed by the foreign companies are usually very enticing to potential customers and promise certain benefits. One of the benefits touted by the manufacturers is that the installation of new equipment will reduce energy costs. An economic analysis of the cost of purchasing and operating PSPs made by the German company "IBAU" versus the corresponding cost of a Russian-made pneumatic chamber pump (PCP) that has built-in energy-saving elements (ESEs) [7 - 14] and has been successfully introduced at Russian plants showed the following:

- the replacement of a PSP by a PCP makes it possible to recoup the investment in 1 year thanks to the savings of electric power that was previously used for the drive of the screw; the replacement also reduced the amount of compressed air needed to transport bulk materials, and it did not require any changes in the diameters of the transport pipes;

- an ESE-equipped PCP is more economical than a PSP because it does have to contain electromechanical equipment to move the product being pumped into the mixing chamber;

- the labor costs incurred in maintaining a PCP are appreciably lower than for a PSP. In addition, the depreciation-related costs of capital pairs of these pumps are 2.4 times lower for PCPs than for PSPs;

- PCPs have a higher utilization factor than PSPs, mainly due to the absence of rapidly worn parts: screw, sleeve, check valve, and electromechanical drive;

- an operating regime which a dense layer of material to be transported with a minimal air-flow rate is practicable only by using pneumatic pumps with a high air pressure PCPs;

- assuming that the both types of pumps are equally productive in moving a given type of material, the amount of air consumed by a PSP is double or more the amount used by a PCP; when the PCP is operated in the dense-bed regime, the two types of pumps differ by a factor of $4-5$ in this regard; 
- the main reason for the inefficiency of PSPs is that the working pressure is often more than 0.15 or $0.1 \mathrm{MPa}$, although it is usually reported to be $2 \mathrm{MPa}$. This is due to the passage of compressed air through the valve and screw in the opposite direction. A PCP makes use of nearly all of the working pressure of the compressor, with pressure inside the chamber ranging from 0.4 to $0.6 \mathrm{MPa}$.

In 2011, the Bereznikovsky Soda Plant completed a successful upgrade on its PSPs, increasing their productivity by $36 \%$. In 2012, the company "ROSMASHINZHINIRING" collaborated with the firm "RUD Ketten" (conveyors, elevators) and the OOO EPTO (pneumatic chamber pumps) to complete a project involving the modernization of three transport lines at the Bereznikovsky plant in accordance with the above recommendations. The upgraded lines have already passed their safety inspections.

\section{REFERENCES}

1. S. A. Evtyukov and M. M. Shapunov, Pneumatic Transport Equipment in the Building Industry and General Construction [in Russian], DNK, St. Petersburg (2005).

2. M. P. Kalinushkin, et al., Pneumatic Transport Equipment: Handbook [in Russian], Mashinostroenie, Leningrad (1986).

3. I. P. Malevich, V. S. Seryakov, and A. V. Mishin, Transport and Storage of Powdered Construction Materials [in Russian], Stroizdat, Moscow (1984).

4. S. Ya. Davydov, Energy-Saving Equipment for the Transport of Bulk Materials: Research, Development, Manufacture [in Russian], UGTU-UPI, Ekaterinburg (2007).

5. M. A. Koshel', I. P. Malevich, V. V. Pitul'ko, and M. M. Shapunov. Author's Certificate No. 509505 RU. Pneumatic Screw
Pump for Transporting Powdered Materials. No. 2000947 / 27 - 11; Sub. 28.02.74; Publ. 05.04.76. Byul. No. 13.

6. S. Ya. Davydov, A. A. Rukomoikin, and A. V. Ponomarev, Patent No. 2252908 RU. Unit for the Pneumatic Transport of Bulk Materials. No. 2003120338; Sub. 02.07.03; Publ. 27.01.05. Byul. No. 15.

7. S. Ya. Davydov, "Ways of increasing productivity in pneumatic transport," S. Ya. Davydov, G. G. Kozhushko, I. D. Kashcheev, and V. A. Matafonova, Novye Ogenupory, No. 4, 26-30 (2011).

8. S. Ya. Davydov, M. A. Pavlukhin, P. S. Byzov, G. A. Veber, S. P. Sidorenko, and V. T. Marichev. Patent No. 1437320 SU. Chamber Feeder for a High-Pressure Pneumatic Conveyor. Byul. No. 42.

9. S. Ya. Davydov, M. A. Pavlukhin, S. P. Sidorenko, and V. T. Marichev, Patent No. 1676970 SU. No. 4725468. Chamber Feeder for a High-Pressure Pneumatic Conveyor. Sub. 01.08.89; Publ. 15.09.91. Byul. No. 34.

10. S. Ya. Davydov, A. V. Ponomarev, G. G. Azenko, and M. A. Pavlukhin, Patent No. 2083458 RU. Chamber Feeder for a HighPressure Pneumatic Conveyor. No. 94038134. Sub. 10.10.94; Publ. 10.07.97. Byul. No. 19.

11. S. Ya. Davydov, A. A. Rukomikin, and A. V. Ponomarev. Patent No. 2189931 RU. Method of Transporting Highly Concentrated Bulk Materials in a Gas Mixture. No. 2000103119. Sub. 08.02.00; Publ. 27.09.02. Byul. No. 27.

12. S. Ya. Davydov, A. V. Kataev, A. A. Rukomoikin, and A. V. Ponomarev. Patent No. 2255889 RU. Chamber Feeder for a Pneumatic Conveyor. No. 2003120339. Sub. 02.07.03; Publ. 10.07.05. Byul. No. 13. S. Ya. Davydov, A. V. Kataev, A. A. Rukomoikin, and A. V. Ponomarev. Patent No. 2255889 RU. Chamber Feeder a for Pneumatic Conveyor. No. 2003120339. Sub. 02.07.03; Publ. 10.07.05. Byul. No. 19.

14. S. Ya. Davydov, "Improving the pneumatic transport of powder materials," S. Ya. Davydov and G. E. Veber, Izv. Vyssh. Uchebn. Zaved. Gorn. Zh., No. 3, 198 - 202 (2000). 